\title{
Prognostic Impact of New-Onset Atrial Fibrillation in Patients With Chronic Heart Failure
}

\author{
- A Report From the CHART-2 Study -
}

Takeshi Yamauchi, MD; Yasuhiko Sakata, MD, PhD; Masanobu Miura, MD, PhD; Soichiro Tadaki, MD; Ryoichi Ushigome, MD; Kenjiro Sato, MD; Takeo Onose, MD;

Kanako Tsuji, MD; Ruri Abe, MD; Takuya Oikawa, MD; Shintaro Kasahara, MD;

Kotaro Nochioka, MD, PhD; Jun Takahashi, MD, PhD; Satoshi Miyata, PhD;

Hiroaki Shimokawa, MD, PhD on behalf of the CHART-2 Investigators

Background: The prognostic impact of new-onset atrial fibrillation (AF) is not fully elucidated.

Methods and Results: We examined 4,818 consecutive stage C/D chronic heart failure (CHF) patients in the Chronic Heart Failure Analysis and Registry in the Tohoku District-2 (CHART-2) Study ( $n=10,219)$. At enrollment, $1,859(38.6 \%)$ of them had AF. Compared with the 2,953 patients without AF, AF patients were characterized by higher age (71 vs. 68 years), lower estimated glomerular filtration rate $\left(58.9\right.$ vs. $\left.61.9 \mathrm{ml} / \mathrm{min} / 1.73 \mathrm{~m}^{2}\right)$, higher brain natriuretic peptide (152 vs. $74.5 \mathrm{pg} / \mathrm{ml}$ ), similar left ventricular ejection fraction (56.8 vs. 56.5\%), and a similar prescription rate of $\beta$-blockers (48.1 vs. $50.6 \%$ ) and renin-angiotensin system (RAS) inhibitors (72.9 vs. $71.6 \%)$. Among the patients without AF at enrollment, 106 (3.6\%) developed new AF during the median 3.2-year follow-up, which was associated with increased mortality (adjusted hazard ratio, 1.72; $P=0.013$ ). In contrast, neither paroxysmal nor chronic AF at enrollment was associated with increased mortality. The mortality rate was significantly high in the first year after the onset of new AF. On inverse probability of treatment weighting analysis using propensity score, RAS inhibitors and statins were associated with reduced incidence of new AF, and diuretics were associated with increase of new AF.

Conclusions: Onset of new AF, but not a history of AF, is associated with increased mortality in CHF patients, especially in the first year. (Circ $J$ 2016; 80: 157-167)

Key Words: Atrial fibrillation; Beta-blocker; Chronic heart failure; Mortality; Renin-angiotensin system inhibitor

A trial fibrillation (AF) is one of the most common comorbidities in patients with heart failure $(\mathrm{HF}),{ }^{1}$ while HF is also commonly observed in AF patients. ${ }^{2}$ Previous studies reported that the prevalence of AF in patients with chronic $\mathrm{HF}$ (CHF) ranged from 15 to $50 \%$. 3-11 Given that AF exerts negative hemodynamic effects by decreasing cardiac output via the loss of atrial contraction, impaired ventricular rate control and triggering ventricular arrhythmias, ${ }^{12,13}$ it is conceivable that the presence of $\mathrm{AF}$ is associated with worse prognosis in CHF patients. It is controversial, however, as to whether $\mathrm{AF}$ is associated with worse prognosis of $\mathrm{CHF}$ patients, ${ }^{3-11}$ partly because standard management of AF has been changing along with implementation of amiodarone, renin-angiotensin system (RAS) inhibitors and $\beta$-blockers and avoidance of class I antiarrhythmic agents. ${ }^{8,10}$ As a result, except for anticoagulation therapies, no established strategy is available to definitely benefit AF patients with $\mathrm{CHF}$ in the current era. ${ }^{14}$ Given that the prevalence of $\mathrm{AF}$ and $\mathrm{CHF}$ is increased with aging, ${ }^{15-18}$ it is important to elucidate the prognostic impact of AF in CHF patients in the era of the aging society, in which the number of HF patients is rapidly increasing. ${ }^{19,20}$ In the present study, we thus examined the prevalence and prognostic impact of AF using the database of the Chronic Heart Failure Analysis and Registry in the Tohoku District-2 (CHART-2) Study. ${ }^{21-25}$

Received July 13, 2015; revised manuscript received October 3, 2015; accepted October 14, 2015; released online December 7, 2015 Time for primary review: 14 days

Department of Cardiovascular Medicine (T.Y., Y.S., M.M., S.T., R.U., K.S., T.O., K.T., R.A., T.O., S.K., K.N., J.T., H.S.), Department of Evidence-Based Cardiovascular Medicine (M.M., S.M., H.S.), Tohoku University Graduate School of Medicine, Sendai, Japan

The Guest Editor for this article was Hiroshi Inoue, MD.

Mailing address: Yasuhiko Sakata, MD, PhD, Department of Cardiovascular Medicine, Tohoku University Graduate school of Medicine, 1-1 Seiryo-machi, Aoba-ku, Sendai 980-8574, Japan. E-mail: sakatayk@ cardio.med.tohoku.ac.jp

ISSN-1346-9843 doi:10.1253/circj.CJ-15-0783

All rights are reserved to the Japanese Circulation Society. For permissions, please e-mail: cj@j-circ.or.jp 


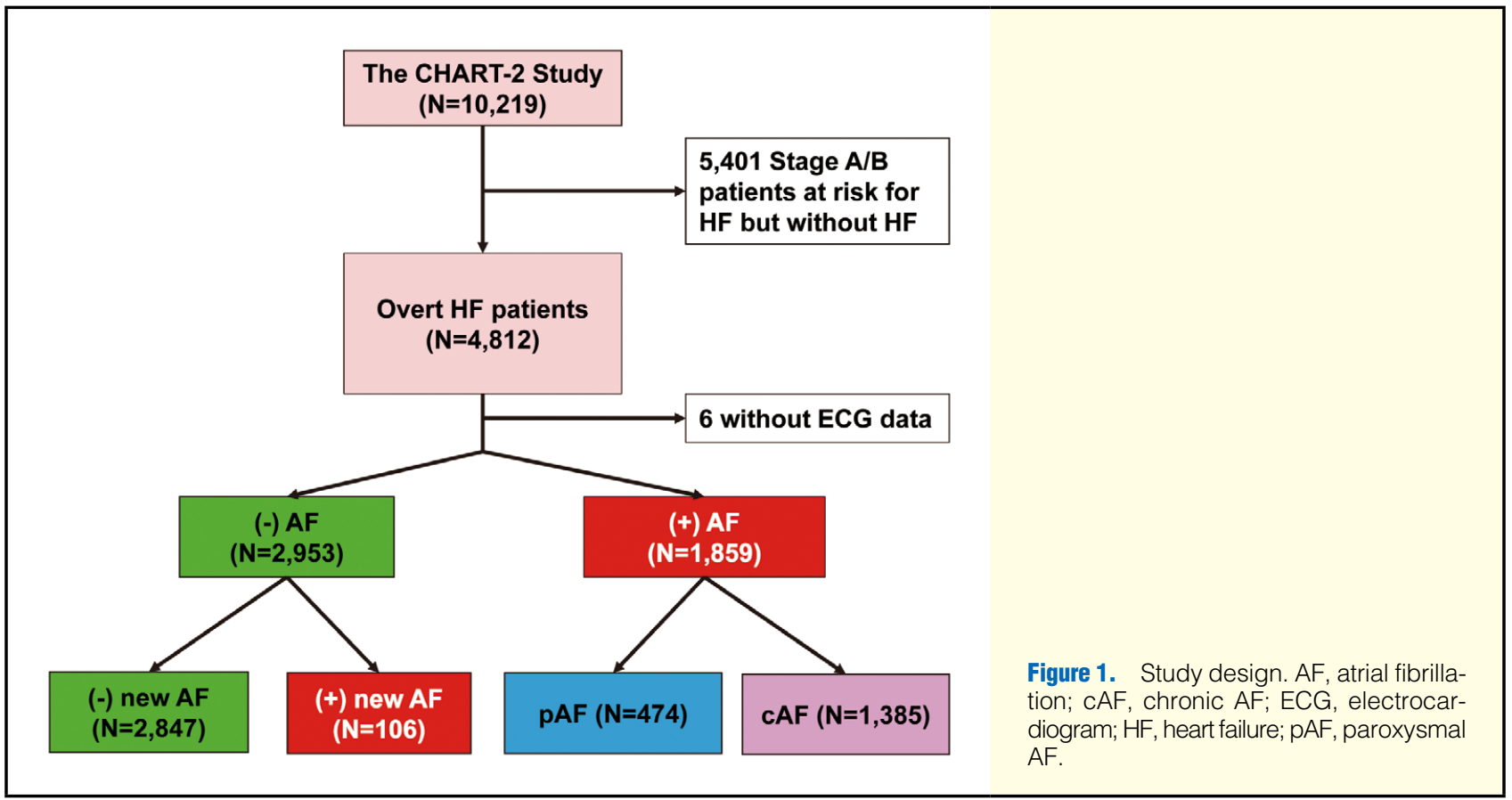

Editorial $p 62$

\section{Methods}

\section{CHART-2 Study}

The CHART-2 Study $(\mathrm{n}=10,219)$ is a multicenter, prospective observational study as previously described in detail (NCT00418041). ${ }^{21-25}$ Briefly, patients aged >20 years with significant coronary artery disease or in stage $B(n=5,401)$ and those with stage $\mathrm{C} / \mathrm{D} \mathrm{HF}(\mathrm{n}=4,818)$ defined according to the ACCF/AHA guidelines ${ }^{26}$ were enrolled between October 2006 and March 2010.21-25 All information was recorded at the time of enrollment, and thereafter annually by trained clinical research coordinators.

\section{Study Design}

The design of the present study is shown in Figure 1. Among the 10,219 patients enrolled, 4,818 had $\mathrm{HF}$ in stage C/D, and 6 of them were excluded due to lack of electrocardiogram data. Among the remaining 4,812 patients, 1,859 (38.6\%) had a history of AF ((+) AF) and 2,953 (61.4\%) did not ((-) AF) at the time of enrollment. Of the 1,859 patients with a history of AF, $474(25.5 \%)$ and 1,385 (74.5\%) had paroxysmal AF (pAF) and chronic $\mathrm{AF}(\mathrm{cAF})$ at the time of registration, respectively. pAF and $\mathrm{cAF}$ were diagnosed by attending physician(s) at each hospital according to the clinical guidelines. ${ }^{16}$ Among 2,953 patients without a history of AF at the time of registration, 106 had newly developed AF during the median 3.8-year follow-up period $((+)$ new AF), while the remaining 2,847 did not ((-) new $\mathrm{AF})$. AF was defined as new $\mathrm{AF}$ if it was the first documentation after enrollment in patients without a history of AF at enrollment. We compared clinical characteristics, treatment and long-term outcomes between $(+)$ $\mathrm{AF}$ and $(-) \mathrm{AF}$, between $(+)$ new $\mathrm{AF}$ and $(-)$ new $\mathrm{AF}$, between pAF and $\mathrm{cAF}$, and among $(+)$ new AF, $(-)$ new $\mathrm{AF}, \mathrm{pAF}$ and cAF patients. The endpoints of the study were all-cause death, $\mathrm{HF}$ admission, cardiovascular (CV) death and non-CV death.
We also examined the prognostic impacts of pAF, cAF and new AF. In order to examine whether new AF has a different prognostic impact from $\mathrm{cAF}$ or $\mathrm{pAF}$, we compared the incidence of the endpoints between patients who developed new $\mathrm{AF}$ without an antecedent HF admission and those with pAF or cAF. Furthermore, in order to examine whether new AF development after HF worsening has a prognostic impact, we also compared the prognosis after HF admission between patients who developed new AF after HF admission and those who did not. In addition, we examined the impact of $\beta$-blockers, RAS inhibitors, calcium channel blockers (CCB), statins and diuretics on the development of new AF.

\section{Statistical Analysis}

All continuous variables are reported as mean \pm SD or median. All categorical variables are represented as frequency (percentage). Fisher's exact test was used to compare categorical variables. Welch's t-test was used to compare continuous variables. Multivariate logistic regression analysis was used to determine the related factors of $\mathrm{AF}$ and those of new $\mathrm{AF}$ at the time of enrollment. Kaplan-Meier method and log-rank test were used to estimate survival curves and HF-free survival curves. To evaluate the impact of AF, new AF, pAF and cAF on incidence of all-cause death, HF admission, CV death or non- $\mathrm{CV}$ death, multivariate Cox proportional hazard models were used. The covariates used in each multivariate analysis were separately chosen by the stepwise method from the following: sex, age, body mass index (BMI), systolic blood pressure (BP), diastolic BP, heart rate, history of hypertension, diabetes mellitus, dyslipidemia, smoking, stroke, AF, malignant disease, $\mathrm{HF}$ admission, etiology of $\mathrm{CHF}$, including ischemic heart disease (IHD), dilated cardiomyopathy (DCM), valvular heart disease (VHD), hypertrophic cardiomyopathy (HCM), hypertension as an etiology of HF (HT), left ventricular (LV) wall thickness, left atrial (LA) dimension, LV dimension (LVD), LV ejection fraction (LVEF), estimated glomerular filtration rate (eGFR), mean corpuscular volume (MCV) of red blood cells, hemoglobin, brain natriuretic peptide (BNP), 
NYHA class, medical treatment, including $\beta$-blockers, CCB, RAS inhibitors, diuretics, statins, anti-platelets, and warfarin. Among these covariates, 22 variables, including sex, age, BMI, diastolic BP, heart rate, history of hypertension, diabetes mellitus, stroke, HF admission, malignant disease, IHD, HT, LV wall thickness, LVEF, eGFR, MCV, hemoglobin, BNP, NYHA class, RAS inhibitors, diuretics and statins, were chosen on the stepwise method.

In the present study, VHD was specifically defined as severe aortic or mitral valvular disease on echocardiography with the use of standard criteria. ${ }^{27} \mathrm{CHF}$ was attributable to HT when a patient did not have IHD, DCM, HCM or VHD, but had a history of HT. Fisher's exact test was used to compare the annual incidence of all-cause death after new AF development between patients who developed new AF without an antecedent $\mathrm{HF}$ admission and those with $\mathrm{pAF}$ and $\mathrm{cAF}$.

We examined the associations between the use of $\beta$-blockers or RAS inhibitors and onset of new AF via the inverse probability of treatment weighting (IPTW) methods using the propensity score (PS). ${ }^{28}$ We calculated PS for $\beta$-blockers and RAS inhibitors with the following covariates: sex, systolic BP, diastolic BP, heart rate, LVD, BMI, BNP, eGFR, age, LVEF,

\begin{tabular}{|c|c|c|c|c|}
\hline $\mathbf{A}$ & All $(n=4,812)$ & (-) AF $(n=2,953)$ & (+) AF $(n=1,859)$ & P-value \\
\hline Female & $1,527(31.7)$ & $913(30.9)$ & $614(33.0)$ & 0.127 \\
\hline Age (years) & $69.0 \pm 12.2$ & $67.7 \pm 13.1$ & $71.0 \pm 10.5$ & $<0.001$ \\
\hline BMI $\left(\mathrm{kg} / \mathrm{m}^{2}\right)$ & $23.3 \pm 5.0$ & $23.6 \pm 5.0$ & $23.0 \pm 4.8$ & $<0.001$ \\
\hline NYHA functional class & & & & $<0.001$ \\
\hline I & $1,123(23.4)$ & $782(26.6)$ & $341(18.4)$ & \\
\hline ॥ & $3,136(65.4)$ & $1,848(62.9)$ & $1,288(69.4)$ & \\
\hline III & $494(10.3)$ & $282(10.0)$ & $212(11.4)$ & \\
\hline IV & $39(0.8)$ & $24(0.8)$ & $15(0.8)$ & \\
\hline \multicolumn{5}{|l|}{ Etiology of CHF } \\
\hline Ischemic heart disease & $2,408(50.1)$ & $1,841(62.3)$ & $567(30.5)$ & $<0.001$ \\
\hline Dilated cardiomyopathy & $633(13.2)$ & $333(11.3)$ & $300(16.1)$ & $<0.001$ \\
\hline $\mathrm{HCM}$ & $138(2.9)$ & $67(2.3)$ & $71(3.8)$ & 0.002 \\
\hline Valvular heart disease & $416(8.7)$ & $175(5.9)$ & $241(13.0)$ & $<0.001$ \\
\hline Hypertension & $950(19.7)$ & $398(13.5)$ & $552(29.7)$ & $<0.001$ \\
\hline \multicolumn{5}{|l|}{ Risk factors } \\
\hline Hypertension & $4,171(86.7)$ & $2,556(86.6)$ & $1,615(86.9)$ & 0.794 \\
\hline Diabetes mellitus & $1,634(34.0)$ & $1,063(36.0)$ & $571(30.7)$ & $<0.001$ \\
\hline Dyslipidemia & $3,773(78.4)$ & $2,454(83.1)$ & $1,319(71.0)$ & $<0.001$ \\
\hline Smoking & $2,106(46.3)$ & $1,330(47.6)$ & $776(44.3)$ & 0.030 \\
\hline \multicolumn{5}{|l|}{ Previous history } \\
\hline Myocardial infarction & $1,630(33.9)$ & $1,307(44.3)$ & $323(17.4)$ & $<0.001$ \\
\hline Stroke & $934(19.4)$ & $495(16.8)$ & $439(23.6)$ & $<0.001$ \\
\hline Malignant disease & $628(13.1)$ & $366(12.4)$ & $262(14.1)$ & 0.095 \\
\hline Admission for heart failure & $2,595(54.0)$ & $1,391(47.1)$ & $1,204(64.8)$ & $<0.001$ \\
\hline \multicolumn{5}{|c|}{ Hemodynamics and LV function } \\
\hline Systolic BP $(\mathrm{mmHg})$ & $126.2 \pm 19.2$ & $127.4 \pm 19.2$ & $124.2 \pm 19.0$ & $<0.001$ \\
\hline Diastolic BP (mmHg) & $72.2 \pm 12.0$ & $72.4 \pm 11.8$ & $71.9 \pm 12.4$ & 0.121 \\
\hline Heart rate (beats/min) & $72.4 \pm 14.9$ & $70.9 \pm 13.3$ & $74.7 \pm 16.9$ & $<0.001$ \\
\hline $\operatorname{LVDd}(\mathrm{mm})$ & $52.1 \pm 9.2$ & $52.3 \pm 9.5$ & $51.9 \pm 8.9$ & 0.168 \\
\hline $\mathrm{LAD}(\mathrm{mm})$ & $42.7 \pm 9.1$ & $39.6 \pm 7.1$ & $47.4 \pm 9.7$ & $<0.001$ \\
\hline LVEF (\%) & $56.6 \pm 15.4$ & $56.5 \pm 15.8$ & $56.8 \pm 14.7$ & 0.495 \\
\hline \multicolumn{5}{|l|}{ Laboratory findings } \\
\hline Hemoglobin (g/dl) & $13.2 \pm 2.0$ & $13.1 \pm 2.0$ & $13.2 \pm 2.1$ & 0.130 \\
\hline eGFR $\left(\mathrm{ml} / \mathrm{min} / 1.73 \mathrm{~m}^{2}\right)$ & $60.7 \pm 21.3$ & $61.88 \pm 22.1$ & $58.85 \pm 19.9$ & $<0.001$ \\
\hline Albumin $(g / d l)$ & $4.1 \pm 0.5$ & $4.1 \pm 0.5$ & $4.0 \pm 0.5$ & 0.005 \\
\hline LDL-C (mg/dl) & $105.0 \pm 30.7$ & $105.0 \pm 30.4$ & $105.0 \pm 31.3$ & 0.981 \\
\hline $\mathrm{BNP}(\mathrm{pg} / \mathrm{ml})$ & 104 & 74.45 & 152 & $<0.001$ \\
\hline \multicolumn{5}{|l|}{ Medications } \\
\hline$\beta$-blockers & $2,362(49.1)$ & $1,420(48.1)$ & $942(50.7)$ & 0.086 \\
\hline RAS inhibitors & $3,485(72.4)$ & $2,154(72.9)$ & $1,331(71.6)$ & 0.320 \\
\hline Diuretics & $2,747(57.1)$ & $1,451(49.1)$ & $1,296(69.7)$ & $<0.001$ \\
\hline Statins & $1,841(38.3)$ & $1,379(46.7)$ & $462(24.9)$ & $<0.001$ \\
\hline Digitalis & $1,135(23.6)$ & $274(9.3)$ & $861(46.3)$ & $<0.001$ \\
\hline
\end{tabular}

(Table 1 continued the next page.) 


\begin{tabular}{|c|c|c|c|c|c|c|c|c|}
\hline B & $\begin{array}{c}\text { All } \\
(n=4,812)\end{array}$ & $\begin{array}{c}(-) \text { New AF } \\
(n=2,847)\end{array}$ & $\begin{array}{c}(+) \text { New AF } \\
(n=106)\end{array}$ & P-value & $\begin{array}{c}\text { pAF } \\
(n=474)\end{array}$ & $\begin{array}{c}\text { CAF } \\
(n=1,385)\end{array}$ & P-value & $\begin{array}{l}\text { P-value } \\
\text { (whole) }\end{array}$ \\
\hline Age (years) & $69.0 \pm 12.2$ & $67.7 \pm 13.1$ & $68.3 \pm 11.9$ & 0.640 & $71.2 \pm 10.4$ & $71.0 \pm 10.5$ & 0.629 & $<0.001$ \\
\hline Female & $1,527(31.7)$ & $882(31.0)$ & $31(29.3)$ & 0.749 & $145(30.6)$ & $469(33.9)$ & 0.194 & 0.227 \\
\hline BMI $\left(\mathbf{k g} / \mathrm{m}^{2}\right)$ & $23.3 \pm 5.0$ & $23.6 \pm 5.1$ & $23.6 \pm 4.7$ & 0.980 & $23.5 \pm 4.1$ & $22.8 \pm 5.1$ & 0.004 & $<0.001$ \\
\hline NYHA class & & & & 0.531 & & & 0.235 & $<0.001$ \\
\hline 1 & $1,123(23.4)$ & $756(26.7)$ & $26(24.8)$ & & $100(21.2)$ & $241(17.4)$ & & \\
\hline II & $3,136(65.4)$ & $1,783(63.0)$ & $65(61.9)$ & & $322(68.2)$ & $966(69.8)$ & & \\
\hline III & $494(10.3)$ & $268(9.5)$ & $14(13.3)$ & & $47(10.0)$ & $165(11.9)$ & & \\
\hline IV & $39(0.8)$ & $24(0.9)$ & $0(0)$ & & $3(0.6)$ & $12(0.9)$ & & \\
\hline \multicolumn{9}{|l|}{ Etiology of CHF } \\
\hline Ischemic heart disease & $2,408(50.1)$ & $1,784(62.7)$ & $57(53.8)$ & 0.067 & $197(41.6)$ & $370(26.7)$ & $<0.001$ & $<0.001$ \\
\hline Dilated cardiomyopathy & $633(13.2)$ & $322(11.3)$ & $11(10.4)$ & 0.876 & $51(10.8)$ & $249(18.0)$ & $<0.001$ & $<0.001$ \\
\hline $\mathrm{HCM}$ & $138(2.9)$ & $59(2.1)$ & $8(7.6)$ & 0.002 & $34(7.2)$ & $37(2.7)$ & $<0.001$ & $<0.001$ \\
\hline Hypertension & $416(8.7)$ & $378(13.3)$ & $20(18.9)$ & 0.110 & $124(26.2)$ & $428(30.9)$ & 0.055 & $<0.001$ \\
\hline Valvular heart disease & $950(19.7)$ & $171(6.0)$ & $4(3.8)$ & 0.526 & $36(7.6)$ & $205(14.8)$ & $<0.001$ & $<0.001$ \\
\hline Others & $228(4.7)$ & $108(3.8)$ & $5(4.7)$ & 0.601 & $28(5.9)$ & $87(6.3)$ & 0.826 & 0.002 \\
\hline \multicolumn{9}{|l|}{ Risk factors } \\
\hline Hypertension & $4,171(86.7)$ & $2,461(86.5)$ & 95 (89.6) & 0.467 & $418(88.2)$ & $1,197(86.4)$ & 0.345 & 0.629 \\
\hline Diabetes mellitus & $1,634(34.0)$ & $1,029(36.1)$ & $34(32.1)$ & 0.412 & 158 (33.3) & $413(30.0)$ & 0.166 & 0.002 \\
\hline Dyslipidemia & $3,773(78.4)$ & $2,365(83.1)$ & $89(84.0)$ & 0.895 & $369(77.9)$ & $950(68.6)$ & $<0.001$ & $<0.001$ \\
\hline Smoking & 2,106 (46.3) & $1,289(47.9)$ & $41(40.2)$ & 0.131 & $210(46.36)$ & $566(43.6)$ & 0.323 & 0.041 \\
\hline \multicolumn{9}{|l|}{ Previous history } \\
\hline Cerebral infarction & $934(19.4)$ & $476(16.7)$ & $19(17.9)$ & 0.693 & $99(20.9)$ & $340(24.6)$ & 0.117 & $<0.001$ \\
\hline Myocardial infarction & $1,630(33.9)$ & $1,267(44.5)$ & $40(37.7)$ & 0.195 & $139(29.3)$ & $184(13.3)$ & $<0.001$ & $<0.001$ \\
\hline Malignant disease & $628(13.1)$ & $354(12.4)$ & $12(11.3)$ & 0.881 & $73(15.4)$ & $189(13.7)$ & 0.359 & 0.248 \\
\hline Admission for HF & $2,595(54.0)$ & $1,341(47.1)$ & $50(47.2)$ & 1.000 & $298(62.9)$ & $906(65.4)$ & 0.317 & $<0.001$ \\
\hline \multicolumn{9}{|c|}{ Hemodynamics and LV function } \\
\hline Systolic BP (mmHg) & $126.2 \pm 19.2$ & $127.34 \pm 19.2$ & $127.1 \pm 19.4$ & 0.884 & $126.1 \pm 20.2$ & $123.6 \pm 18.5$ & 0.017 & $<0.001$ \\
\hline Diastolic BP (mmHg) & $72.2 \pm 12.0$ & $72.4 \pm 11.8$ & $72.3 \pm 11.6$ & 0.903 & $71.6 \pm 13.0$ & $72.0 \pm 12.1$ & 0.590 & 0.154 \\
\hline Heart rate (beats/min) & $72.4 \pm 14.9$ & $70.9 \pm 13.4$ & $70.3 \pm 12.4$ & 0.641 & $69.8 \pm 14.5$ & $76.4 \pm 17.3$ & $<0.001$ & $<0.001$ \\
\hline $\operatorname{LAD}(\mathrm{mm})$ & $52.1 \pm 9.2$ & $39.4 \pm 7.0$ & $43.2 \pm 8.6$ & $<0.001$ & $42.5 \pm 8.0$ & $49.1 \pm 9.6$ & $<0.001$ & $<0.001$ \\
\hline LVDd (mm) & $42.7 \pm 9.1$ & $52.2 \pm 9.4$ & $53.5 \pm 11.0$ & 0.261 & $51.4 \pm 8.7$ & $52.0 \pm 8.9$ & 0.179 & 0.358 \\
\hline $\operatorname{LVEF}(\%)$ & $56.6 \pm 15.4$ & $56.5 \pm 15.8$ & $55.2 \pm 15.7$ & 0.412 & $57.6 \pm 15.3$ & $56.5 \pm 14.5$ & 0.179 & 0.766 \\
\hline \multicolumn{9}{|l|}{ Laboratory findings } \\
\hline Hemoglobin (g/dl) & $13.2 \pm 2.0$ & $13.1 \pm 2.0$ & $13.2 \pm 2.2$ & 0.587 & $13.2 \pm 1.9$ & $13.2 \pm 2.1$ & 0.531 & 0.094 \\
\hline eGFR $\left(\mathrm{ml} / \mathrm{min} / 1.73 \mathrm{~m}^{2}\right)$ & $60.7 \pm 21.3$ & $62.0 \pm 22.2$ & $59.3 \pm 20.5$ & 0.189 & $57.8 \pm 20.0$ & $59.2 \pm 20.0$ & 0.185 & $<0.001$ \\
\hline Albumin $(g / d l)$ & $4.1 \pm 0.5$ & $4.1 \pm 0.5$ & $4.1 \pm 0.5$ & 0.791 & $4.1 \pm 0.5$ & $4.0 \pm 0.5$ & 0.235 & 0.003 \\
\hline LDL-C (mg/dl) & $105.0 \pm 30.7$ & $104.8 \pm 30.4$ & $109.8 \pm 29.8$ & 0.156 & $106.2 \pm 33.0$ & $104.6 \pm 30.6$ & 0.456 & 0.987 \\
\hline $\mathrm{BNP}(\mathrm{pg} / \mathrm{ml})$ & 104 & 70.7 & 158 & 0.035 & 114.5 & 169 & 0.015 & $<0.001$ \\
\hline \multicolumn{9}{|l|}{ Medications } \\
\hline$\beta$-blockers & $2,362(49.1)$ & $1,366(48.0)$ & $54(50.9)$ & 0.554 & $245(51.7)$ & $697(50.3)$ & 0.632 & 0.311 \\
\hline RAS inhibitors & $3,485(72.4)$ & $2,079(73.0)$ & $75(70.8)$ & 0.580 & $328(69.2)$ & $1.003(72.4)$ & 0.194 & 0.367 \\
\hline Diuretics & $2,747(57.1)$ & $1,382(48.5)$ & $69(65.1)$ & 0.001 & $271(57.2)$ & $1,025(74.0)$ & $<0.001$ & $<0.001$ \\
\hline Statins & 1,841 (38.3) & $1,345(47.2)$ & $34(32.1)$ & 0.002 & 149 (31.4) & $313(22.6)$ & $<0.001$ & $<0.001$ \\
\hline Digitalis & $1,135(23.6)$ & $257(9.0)$ & $17(16.0)$ & 0.001 & $140(29.5)$ & 721 (52.1) & $<0.001$ & $<0.001$ \\
\hline Aspirin & 2,766 (57.5) & $1,803(63.3)$ & $61(57.6)$ & 0.259 & 262 (55.3) & 640 (46.2) & 0.001 & $<0.001$ \\
\hline Warfarin & $1,871(38.9)$ & $576(20.2)$ & $26(24.5)$ & 0.271 & $260(54.9)$ & $1,009(72.9)$ & $<0.001$ & $<0.001$ \\
\hline
\end{tabular}

Data given as mean \pm standard deviation, median of $n(\%)$. AF, atrial fibrillation; BMI, body mass index; BNP, brain natriuretic peptide; BP, blood pressure; $C A F$, chronic atrial fibrillation; eGFR, estimated glomerular filtration rate; HCM, hypertrophic cardiomyopathy; HF, heart failure; LAD, left atrial dimension; LDL-C, low-density lipoprotein cholesterol; LVDd, left ventricular diastolic dimension; LVEF, left ventricular ejection fraction; NYHA, New York Heart Association; pAF, paroxysmal atrial fibrillation; RAS, renin-angiotensin system.

history of HF admission, HT, diabetes mellitus, dyslipidemia, malignant disease, hemoglobin, MCV, NYHA class, use of $\beta$-blockers (for PS of RAS inhibitors only), RAS inhibitors (for PS of $\beta$-blockers only), diuretics, CCB, and digitalis, LV wall thickness and LA dimension. All statistical analysis was performed using $\mathrm{R}$ version $3.1 .1 .{ }^{29} \mathrm{P}<0.05$ was considered to be statistically significant.

\section{Results}

\section{Factors Associated With AF in CHF Patients}

Baseline characteristics are listed in Table 1A. Patients with $\mathrm{AF}$, as compared with those without it, were characterized by higher age, lower BMI, lower eGFR, higher prevalence of prior stroke, and lower prevalence of diabetes mellitus and 
dyslipidemia. AF patients had lower prevalence of IHD and higher prevalence of DCM, HCM, VHD and HT. AF patients were more frequently treated with diuretics and digitalis, whereas there was no significant difference in the use of $\beta$-blockers or RAS inhibitors. As compared with patients without AF, AF patients had higher NYHA functional class, increased BNP and larger LA dimension, but had similar LVEF. Table 1B lists the baseline characteristics of patients in the 4 groups defined as (-) new $\mathrm{AF},(+)$ new $\mathrm{AF}, \mathrm{pAF}$ and $\mathrm{cAF}$. Among the patients with AF, those with pAF, as compared with those with $\mathrm{CAF}$, had higher BMI, higher prevalence of IHD, dyslipidemia and history of myocardial infarction, smaller LA dimension and decreased use of diuretics. Table 2 lists the factors associated with $\mathrm{AF}$ at enrollment and those predictive for development of new AF.

\section{Prognostic Impact of AF in CHF}

There were 732 deaths and $762 \mathrm{HF}$ admissions during the median follow-up of 3.2 years. The cause of death was CV death in 337, non-CV death in 276 and unknown in 119. Among the 2,953 patients without a history of AF at enrollment, $106(3.6 \%)$ developed new AF with an annual incidence of approximately $1.2 \%$. Among them, 78 developed new AF without any antecedent $\mathrm{HF}$ admission, 13 developed new AF after $\mathrm{HF}$ admission and, in the remaining 15 patients, new $\mathrm{AF}$ was documented on the same day of HF admission. Using Kaplan-Meier estimates and the univariate Cox proportional hazard models for all-cause death and HF admission, patients with AF had significantly higher incidences of all-cause death, $\mathrm{HF}$ admission, $\mathrm{CV}$ death and non-CV death (Figure 2), and those with new AF, pAF and cAF had increased incidence of death and $\mathrm{HF}$ admission compared with those without new AF (Figures 3A,B). As compared with patients without new AF, those with new AF had an increased incidence of $\mathrm{CV}$ death, but not had increased incidence of non-CV death, while those with $\mathrm{pAF}$ and those with $\mathrm{cAF}$ tended to have, or had increased incidences of $\mathrm{CV}$ death and non-CV death, respectively (Figures 3C,D). On multivariate Cox regression analysis for all-cause death and HF admission, history of AF at enrollment was not associated with all-cause death or HF admission (Figure 4A). Compared with patients without new AF, however, those with new AF had increased risk of all-cause death and HF admission, and those with pAF, but not those with $\mathrm{cAF}$, had increased risk of $\mathrm{HF}$ admission (Figure 4B). Given that the impact of $\mathrm{cAF}$ and of $\mathrm{pAF}$ on all-cause death were not significantly different, we combined both groups in subsequent analysis. Importantly, the incidence of all-cause death and of $\mathrm{HF}$ admission were significantly higher in patients with new AF observed from its onset compared with those with $\mathrm{AF}$ at enrollment (all-cause death: hazard ratio (HR), 2.27; $\mathrm{P}=0.001$; HF admission: HR, 1.68; $\mathrm{P}=0.037$; Figures 5A,B). The patients with new AF, however, as compared with those with $\mathrm{AF}$ at enrollment, had an increased incidence of $\mathrm{CV}$ death but not of non-CV death (Figures 5C,D). In the patients with new $\mathrm{AF}$, the annual mortality rate was significantly higher in the first year compared with those with cAF (Figure 5E). Among the patients who had HF admission during the follow-up, the mortality did not differ significantly between patients with new AF after HF admission and those without it (Figure 5F).

\section{Use of Beta-Blockers and RAS Inhibitors and Onset of New AF}

Relationships between medications and new AF development are shown in Figure 6. Use of RAS inhibitors and of statins were associated with a reduced incidence of new AF, while

\begin{tabular}{|lrr|}
\hline Table 2. Factors Related to AF & & \\
Clinical characteristics & OR & P-value \\
Factors related to AF at enrollment & & \\
Female sex & 0.67 & $<0.001$ \\
Age & 1.02 & $<0.001$ \\
BMI & 0.96 & $<0.001$ \\
Systolic BP & 0.99 & $<0.001$ \\
Diastolic BP & 1.01 & 0.023 \\
Heart rate & 1.01 & $<0.001$ \\
History of HF admission & 1.79 & $<0.001$ \\
Dyslipidemia & 0.66 & $<0.001$ \\
History of stroke & 1.41 & 0.001 \\
Ischemic heart disease & 0.35 & $<0.001$ \\
Hypertensive heart disease & 1.37 & 0.006 \\
LV wall thickness & 0.95 & $<0.001$ \\
LAD & 1.15 & $<0.001$ \\
LVDd & 0.95 & $<0.001$ \\
eGFR & 0.99 & 0.060 \\
MCV & 1.01 & 0.071 \\
Hemoglobin & 1.17 & $<0.001$ \\
NYHA class & 1.17 & 0.033 \\
Factors related to new AF during follow-up & & \\
HCM & 3.96 & 0.003 \\
Hypertensive heart disease & 2.12 & 0.007 \\
LA dimension & 1.06 & $<0.001$ \\
MCV & 1.05 & 0.025 \\
Diuretics & 1.91 & 0.011 \\
\hline
\end{tabular}

MCV, multiple corpuscular volume; OR, odds ratio. Other abbreviations as in Table 1.

that of diuretics was associated with an increased incidence of new AF. Use of $\beta$-blockers and of CCB were not associated with incidence of new AF development.

\section{Discussion}

The major findings of the present study were that (1) more than one-third of CHF patients had current or past history of $\mathrm{AF}$, with an unadjusted increased risk of death and HF admission; (2) given that AF patients were characterized by worse clinical profiles such as higher age, impaired renal function and higher NYHA classes, adjusted prognostic risk of AF was insignificant; (3) among the patients without history of AF at enrollment, approximately $1.2 \%$ developed new AF annually with an increased risk of death, which was highest in the first year after the onset; and (4) use of RAS inhibitors and of statins were associated with decreased incidence of development of new AF. These findings are clinically important because an understanding of the current impact of AF is crucial for better management of $\mathrm{CHF}$ patients in the current aging society.

Characteristics and Prevalence of AF in the CHART-2 Study In the present study, AF patients were characterized by higher age, higher BNP, higher NYHA class, lower prevalence of IHD and higher prevalence of HT and DCM as etiology of CHF, which were similar findings in the previous studies. ${ }^{5,6,8}$ Furthermore, prior or current history of AF was present in $38.6 \%$ of the present CHF patients. Although this prevalence was within the previously reported range $(15-50 \%),{ }^{3-11}$ the prevalence was the highest except for the CONCENSUS Trial, in which the prevalence of AF was $50 \%$ in patients with 
A

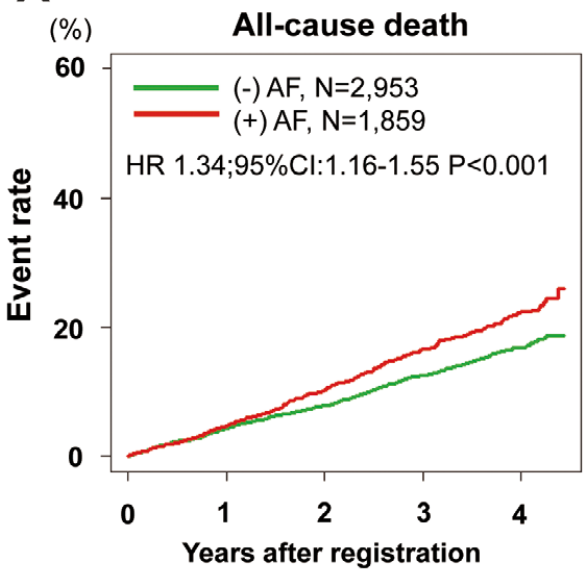

C

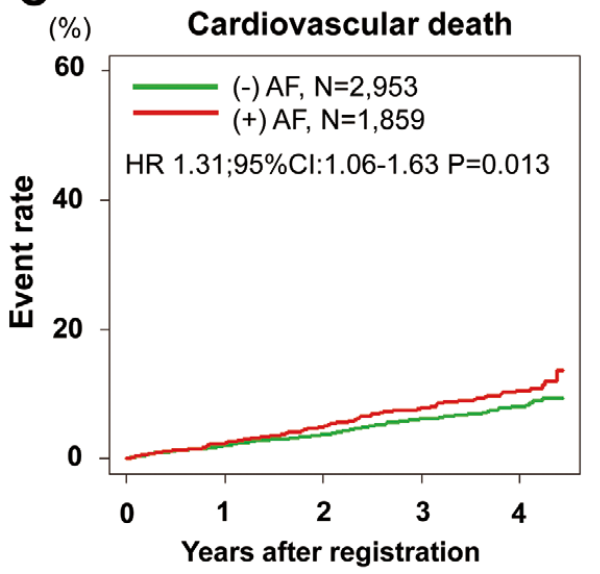

B

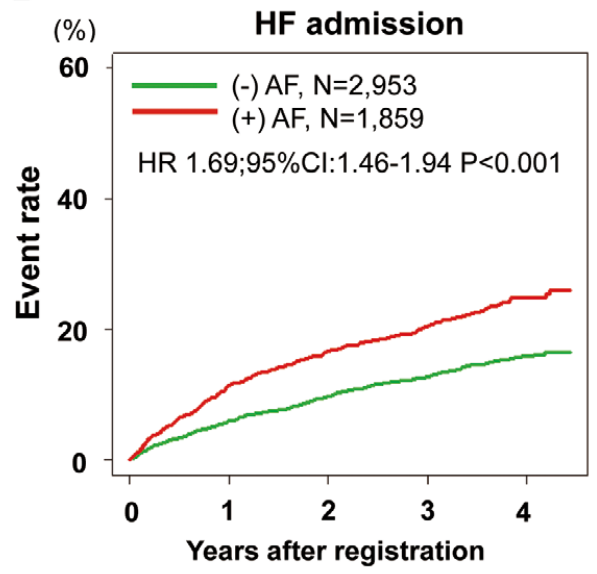

D

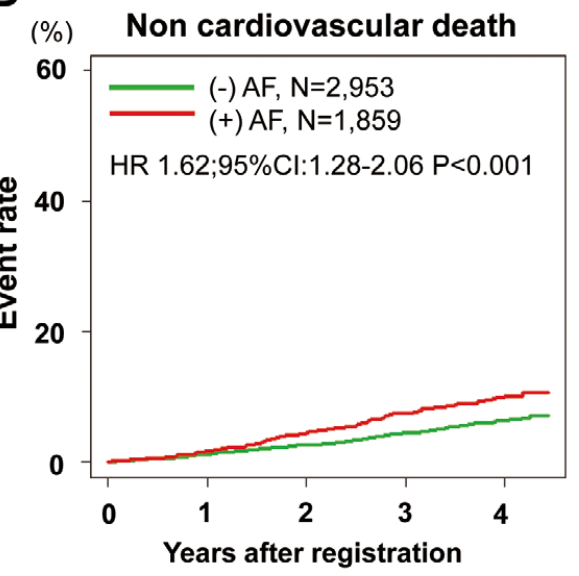

Figure 2. Kaplan-Meier estimates for (A) all-cause death, (B) heart failure (HF) admission, (C) cardiovascular death and (D) noncardiovascular death. Curves for patients with atrial fibrillation $(A F ;(+) A F)$ and those without $A F((-) A F)$ at enrollment.

severe HF in NYHA class IV. ${ }^{11}$ Given that Hamaguchi et al also reported that the prevalence of $\mathrm{AF}$ was $35 \%$ among the Japanese patients with hospitalized HF in the JCARE-CARD, ${ }^{9}$ Japanese patients with CHF might have a higher prevalence of AF as compared with Western patients with CHF. Another explanation could be the relatively preserved LVEF (mean $56 \%$ ) in the present study, given that a similar prevalence of AF (36\%) was reported among hospitalized French patients with preserved LVEF (HFpEF).

\section{Incidence and Risk Factors of New AF}

In the present study, 106 of 2,953 patients without a history of AF (3.6\%) developed new AF during the median 3.2-year follow-up, with an annual incidence of approximately $1.2 \%$. The predictive factors of new AF in the present study included larger LA dimension, higher MCV, prescription of diuretics, and prevalence of HCM and HT as etiology of CHF, all of which were characteristics of elderly HF or HFpEF patients. In general, the incidence of new $\mathrm{AF}$ was more frequent in patients with $\mathrm{CHF}$ than in the general population. Indeed, in the present study, the annual incidence of new AF was higher than in the general population: $0.3-0.5 \%$ in the Framingham
Heart Study ${ }^{15}$ and $0.3 \%$ in the Hisayama Study in Japan, ${ }^{16}$ although it was lower than that in the Caucasian patients with CHF (3-5\%). ${ }^{13,29}$

\section{Prognostic Impact of AF in CHF}

In the present study, neither pAF nor cAF was associated with mortality after adjustment for clinical background, although both types of AF were associated with all-cause mortality on univariate analysis, a consistent finding with the previous reports. ${ }^{4,5,7-9,30}$ In contrast, the present study clearly demonstrates that new AF was significantly associated with increased incidence of all-cause death and HF admission. The present study also showed that patients with pAF did not have increased incidence of all-cause death, but had increased incidence of HF admission (Figure 4). Thus, it is conceivable that new AF or pAF, but not cAF, could cause acute change of hemodynamics by decreasing cardiac output or disturbing appropriate heart rhythm, resulting in worse prognosis in $\mathrm{CHF}$ patients. Given that the prognostic impact of new AF was noted on $\mathrm{CV}$ death, but not on non-CV death, it is also conceivable that the hemodynamic change by new AF or pAF might have affected the prognosis of CHF patients. In the present study, 

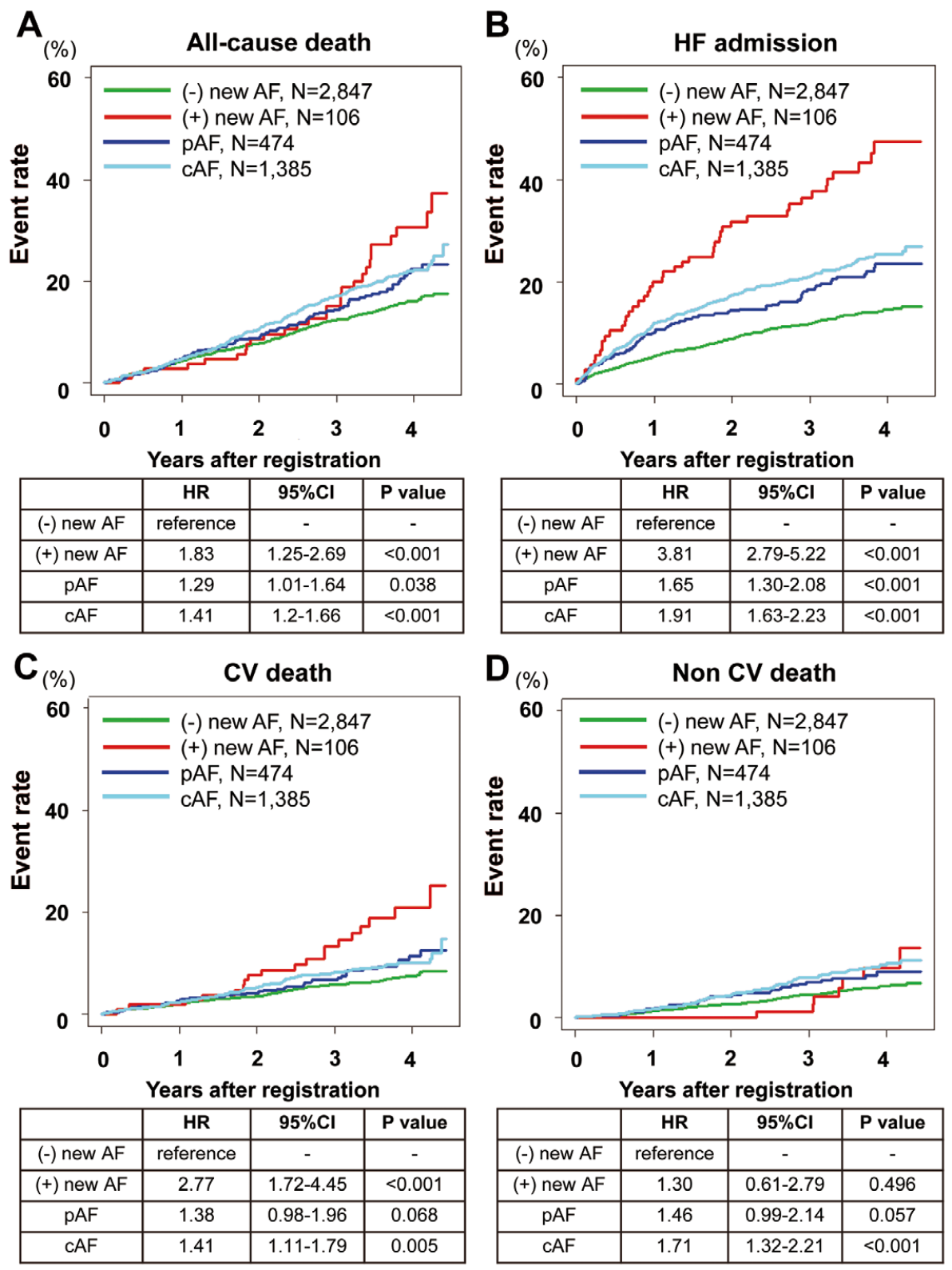

Figure 3. Kaplan-Meier estimates for (A) all-cause death, (B) heart failure (HF) admission, (C) cardiovascular (CV) death and (D) non-CV death for patients with new atrial fibrillation (AF; (+) new AF), without new $A F((-)$ new $A F)$, with paroxysmal $A F(p A F)$ and those with chronic AF (cAF).

pAF, as compared with new AF, had a small impact on HF admission and no impact on all-cause death, which could be explained by the length of time elapsed since the onset of AF, given that the prognostic impact of new AF was evident in the first year of new AF onset. Thus, conversion of AF and maintenance of sinus rhythm with pharmacological or non-pharmacological therapies may be most effective within the first year of new AF onset. Considering the smaller LA dimensions in the patients with new AF or pAF, conversion to sinus rhythm and/or maintenance of sinus rhythm is likely to be easier and more appropriate for those with new AF or pAF than for those with cAF. It should be noted, however, that the increased prognostic risk after the onset of new AF could also be explained by adverse effects of medications initiated after the onset of new AF. Thus, radiofrequency catheter ablation (RFCA) for AF should be indicated shortly after the onset of new AF. It remains to be determined, however, whether RFCA for AF improves long-term prognosis of CHF patients, although it has been shown to improve peak oxygen consumption and LVEF in $\mathrm{HF}$ patients with reduced $\mathrm{EF} .{ }^{31}$

\section{Prognostic Impact of New AF in CHF}

In the present study, new AF had a significant prognostic impact, particularly in the first year after the onset of new AF. 
A

$$
\text { Events / N HR }(95 \% \mathrm{Cl}) \quad \mathrm{P} \text { value }
$$

\begin{tabular}{|c|c|c|c|}
\hline \multicolumn{4}{|l|}{ All-cause death } \\
\hline$(-) A F$ & 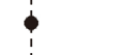 & $328 / 2,453$ & reference \\
\hline$(+) \mathrm{AF}$ & -1 & $289 / 1,626$ & $0.99(0.83-1.17) 0.873$ \\
\hline \multicolumn{4}{|l|}{ HF admission } \\
\hline$(-) A F$ & $\varphi$ & $317 / 2,413$ & reference \\
\hline (+) $\mathrm{AF}$ & •-1 & $332 / 1,606$ & $1.13(0.94-1.35) 0.196$ \\
\hline & 1.5 & & \\
\hline
\end{tabular}

B

Events / N HR $(95 \% \mathrm{Cl}) \quad$ P value

\begin{tabular}{|c|c|c|c|c|}
\hline \multicolumn{5}{|l|}{ All-cause death } \\
\hline$(-)$ new AF & 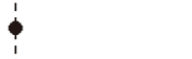 & $305 / 2,367$ & reference & \\
\hline$(+)$ new AF & $\mapsto$ & $23 / 86$ & $1.72(1.12-2.64)$ & 0.013 \\
\hline $\mathrm{pAF}$ & $i$ & $71 / 419$ & $1.10(0.84-1.43)$ & 0.491 \\
\hline $\mathrm{cAF}$ & 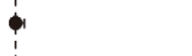 & $218 / 1,207$ & $1.00(0.82-1.21)$ & 0.992 \\
\hline \multicolumn{5}{|l|}{ HF admission } \\
\hline (-) new AF & i & 282 / 2,329 & reference & \\
\hline$(+)$ new AF & $\longmapsto$ & $35 / 83$ & $3.31(2.32-4.73)$ & $<0.001$ \\
\hline $\mathrm{pAF}$ & :-er & $78 / 409$ & $1.46(1.13-1.89)$ & 0.004 \\
\hline \multirow[t]{2}{*}{$\mathrm{CAF}$} & is & $254 / 1,197$ & $1.17(0.95-1.43)$ & 0.138 \\
\hline & 3 & & & \\
\hline
\end{tabular}

Figure 4. (A) Univariate and (B) multivariate Cox proportional regression analysis for all-cause death and heart failure (HF) admission. Circles, hazard ratio (HR); horizontal lines, $95 \% \mathrm{Cl}$ calculated using inverse probability of treatment weighting. $A F$, atrial fibrillation; $c A F$, chronic AF; $p A F$, paroxysmal AF.
Indeed, it has been considered that $\mathrm{HF}$ and AF may directly predispose to each other. , $2,30,32,33$ Wang et al examined 1,470 individuals who developed new $\mathrm{AF}, \mathrm{CHF}$, or both in the Framingham Heart Study, demonstrating that later development of new AF was associated with increased mortality in CHF subjects. ${ }^{30}$ Moreover, pre-existing CHF adversely affected survival in individuals with new AF, while pre-existing AF was not associated with an adverse survival in those with $\mathrm{CHF}^{34}$ It is still controversial, however, whether new AF has a prognostic impact independently of antecedent HF admission in patients with CHF. ${ }^{13,35}$ In the present study, it should be noted that new AF that developed without an antecedent hospitalization for HF had increased incidence of all-cause death shortly after new AF development, whereas new AF development after HF admission did not have any prognostic impact. Thus, new AF may have a prognostic impact only when it develops without antecedent HF worsening.

\section{Prevention of AF in CHF Patients}

In the present study, IPTW analysis showed that treatment with RAS inhibitors and statins was related to a decrease of new onset AF. Given that new-onset AF was significantly associated with poor prognosis in the present study, prevention of new AF with RAS inhibitors or statins is important to improve the prognosis of CHF patients. In this regard, RAS inhibition may be important given that several studies reported the benefits of RAS inhibitors to prevent new AF in CHF patients. ${ }^{36,37}$ Indeed, we have recently reported that, in hypertensive patients with CHF, combination of angiotensin-converting enzyme inhibitors (ACEI) and olmesartan, but not triple combination of ACEI, $\beta$-blockers and olmesartan, could be useful to reduce new AF. ${ }^{38}$ In contrast, it is controversial as to whether statins are effective to reduce the onset of AF. ${ }^{39-43}$ In patients without $\mathrm{HF}$, statin use was not associated with reduced incidence of new-onset AF except in the JUPITER Trial, ${ }^{39}$ which enrolled patients with high-sensitivity C-reactive protein $\geq 2.0 \mathrm{mg} / \mathrm{L}$, while it was reported that statin use was associated with reduced incidence of new onset $\mathrm{AF}$ in patients with $\mathrm{HF},{ }^{40,43}$ consistent with the present study. Thus, statins could be useful to prevent new-onset AF in patients with $\mathrm{HF}$ or inflammation, a pathological condition of HF. Thus, prevention of AF with RAS inhibition or statin use could be one of the most important therapeutic strategies in the management of $\mathrm{CHF}$, although further clinical examination is warranted.

\section{Study Limitations}

Several limitations should be mentioned for the present study. First, the number of new AF patients was relatively small, which might have limited the power of the statistical analysis. Second, we did not have sufficient data to evaluate LA size other than LA dimension. Thus, it could be possible that evaluation of LA size was not accurate. ${ }^{44}$ Third, we did not have sufficient data to define the duration of AF in each patient. Fourth, the prognostic impact of $\beta$-blockers and of RAS inhibitors were analyzed based on the initial data at enrollment, and we did not include information on the doses of and adherence to these drugs during the follow-up period. Finally, because CHART-2 is a prospective observational study, the present results need to be carefully interpreted when generalizing to other populations. 

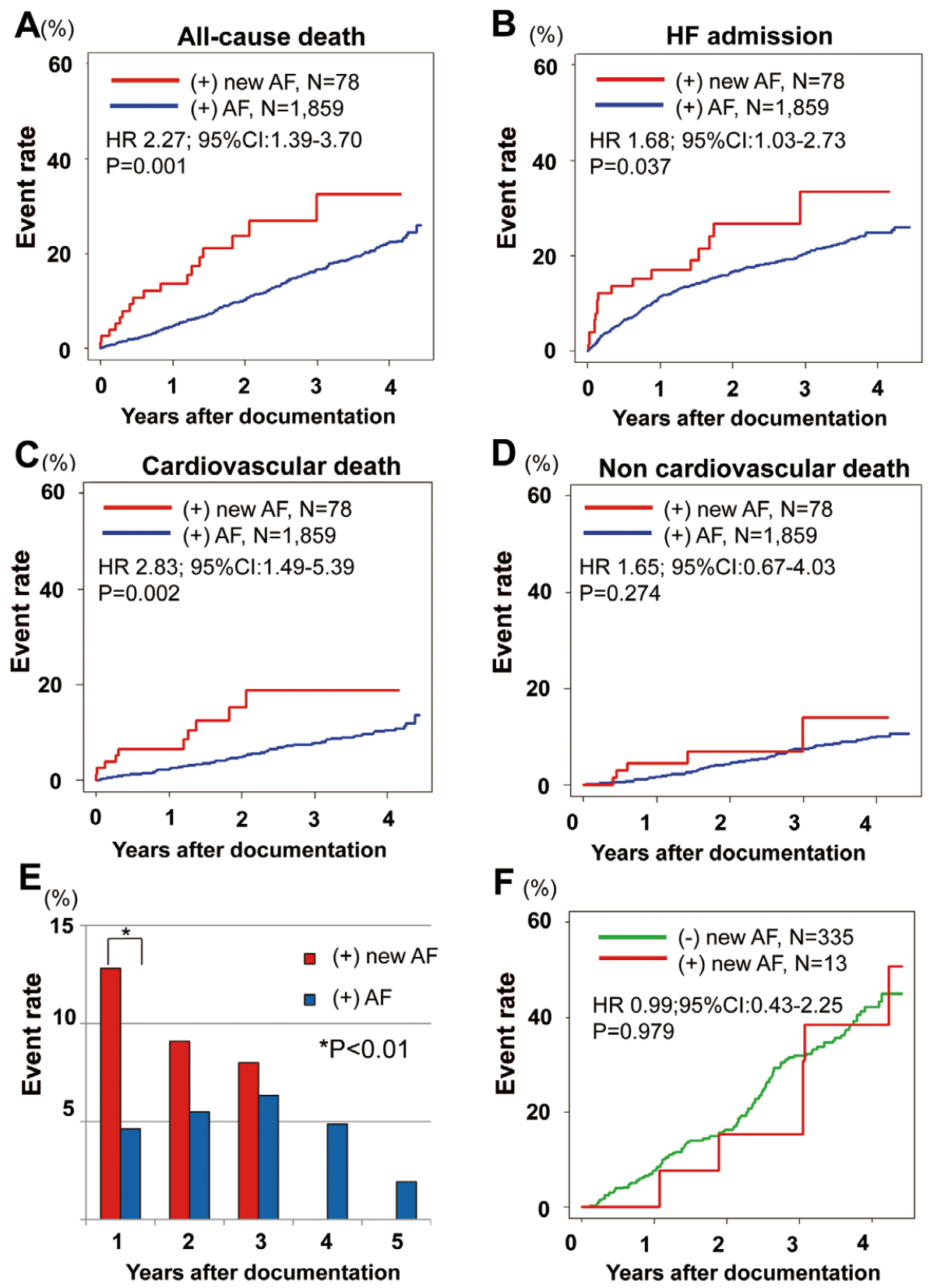

Figure 5. Kaplan-Meier estimates for (A) all-cause death, (B) heart failure (HF) admission, (C) cardiovascular death and (D) noncardiovascular death after the onset of new atrial fibrillation (AF) in patients with new AF and after enrollment in patients with $A F$; (E) rate of all-cause death in each year after the onset of new AF in patients with new AF, and that after enrollment in patients with $\mathrm{AF}$; and (F) Kaplan-Meier estimates for all-cause death after the day of HF admission in patients with HF admission. CAF, chronic AF; pAF, paroxysmal AF.

\section{Conclusions}

Development of new AF, but not a history of pAF or cAF, was associated with increased mortality in CHF patients, suggesting that $\mathrm{dnAF}$ is an important therapeutic target in the management of $\mathrm{CHF}$.

\section{Acknowledgments}

We thank all the members of the Tohoku Heart Failure Society and the staff of the Departments of Cardiovascular Medicine and Evidence-based Cardiovascular Medicine, Tohoku University Graduate School of Medicine for their contributions (Supplementary File 1). This study was supported in part by the Grants-in Aid from the Ministry of Health, Labour, and Welfare and the Ministry of Education, Culture, Sports, Science, and Technology, Japan.

\section{Disclosures}

The Department of Evidence-based Cardiovascular Medicine, Tohoku University Graduate School of Medicine, is supported in part by the 


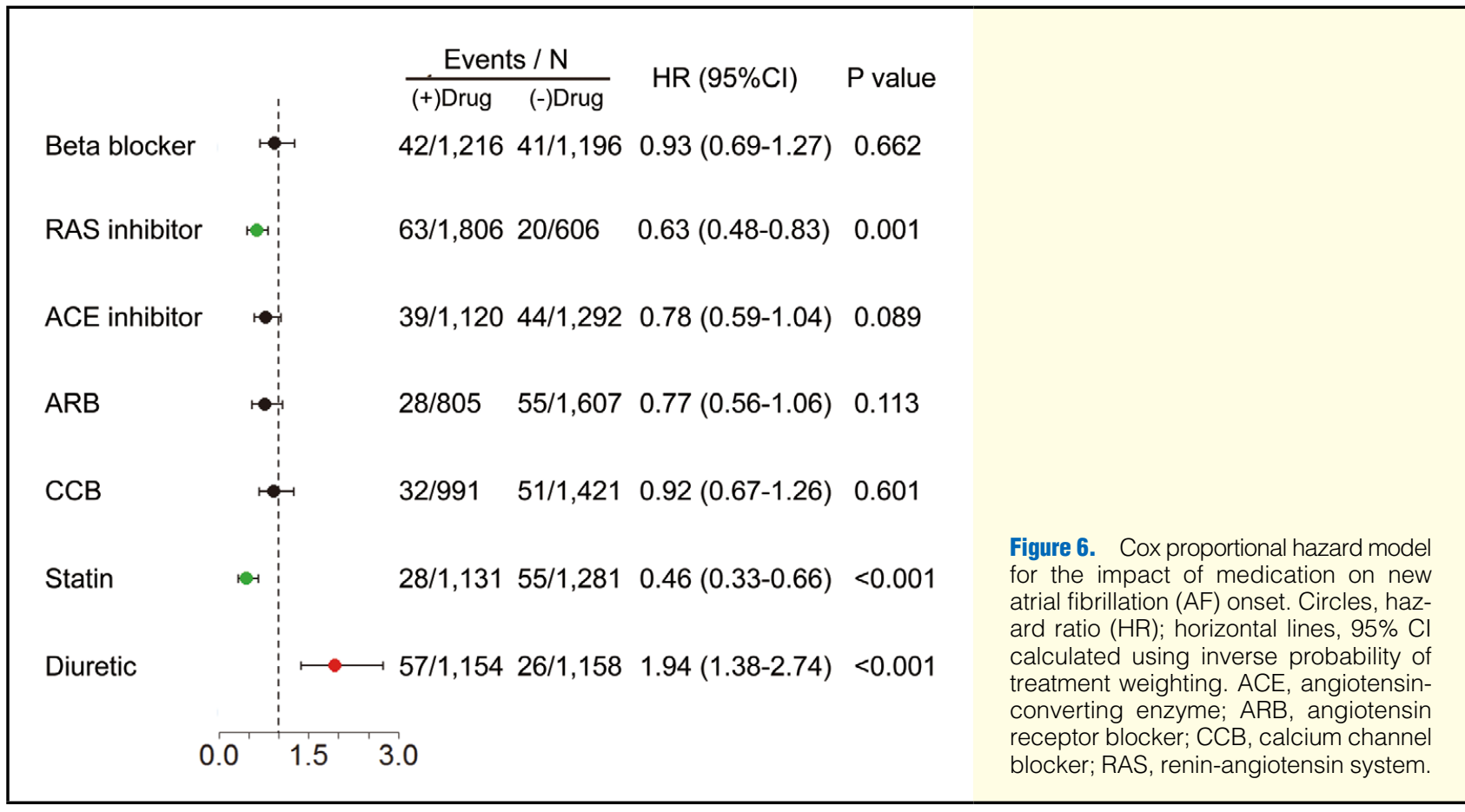

unrestricted research grants from Daiichi Sankyo (Tokyo, Japan), Bayer Yakuhin (Osaka, Japan), Kyowa Hakko Kirin (Tokyo, Japan), Kowa Pharmaceutical (Tokyo, Japan), Novartis Pharma (Tokyo, Japan), Dainippon Sumitomo Pharma (Osaka, Japan), and Nippon Boehringer Ingelheim (Tokyo, Japan). H.S. has received lecture fees from Bayer Yakuhin (Osaka, Japan), Daiichi Sankyo (Tokyo, Japan) and Novartis Pharma (Tokyo, Japan).

\section{References}

1. Maisel WH, Stevenson LW. Atrial fibrillation in heart failure: Epidemiology, pathophysiology, and rationale for therapy. Am J Cardiol 2003; 91(Suppl): 2D-8D.

2. Benjamin EJ, Levy D, Vaziri SM, D'Agostino RB, Belanger AJ, Wolf PA. Independent risk factors for atrial fibrillation in a population-based cohort: The Framingham heart study. JAMA 1994; 271: $840-844$.

3. Middlekauff HR, Stevenson WG, Stevenson LW. Prognostic significance of atrial fibrillation in advanced heart failure: A study of 390 patients. Circulation 1991; 84: 40-48.

4. Swedberg K, Olsson LG, Charlesworth A, Cleland J, Hanrath P, Komajda M, et al. Prognostic relevance of atrial fibrillation in patients with chronic heart failure on long-term treatment with betablockers: Results from COMET. Eur Heart J 2005; 26: 1303-1308.

5. Rusinaru D, Leborgne L, Peltier M, Tribouilloy C. Effect of atrial fibrillation on long-term survival in patients hospitalized for heart failure with preserved ejection fraction. Eur J Heart Fail 2008; 10: $566-572$.

6. Dries DL, Exner DV, Gersh BJ, Domansuki MJ, Waclawiw MA, Stevenson LW. Atrial fibrillation is associated with an increased risk for mortality and heart failure progression in patients with asymptomatic and symptomatic left ventricular systolic dysfunction: A retrospective analysis of the SOLVD trials. J Am Coll Cardiol 1998; 32: $695-703$.

7. Kober L, Swedberg K, McMurray JJV, Pfeffer MA, Velazquez EJ, Diaz R, et al. Previously known and newly diagnosed atrial fibrillation: A major risk indicator after a myocardial infarction complicated by heart failure or left ventricular dysfunction. Eur J Heart Fail 2006; 8: $591-598$.

8. Olsson LG, Swedberg K, Ducharme A, Granger CB, Michelson EL, McMurray JJ, et al. Atrial fibrillation and risk of clinical events in chronic heart failure with and without left ventricular systolic dysfunction: Results from the Candesartan in Heart failure-Assessment of Reduction in Mortality and morbidity (CHARM) program. $J$ Am Coll Cardiol 2006; 47: 1997-2004.
9. Hamaguchi S, Yokoshiki H, Kinugawa S, Tsuchihashi M, Yokota T, Takeshita A, et al. Effects of atrial fibrillation on long-term outcomes in patients hospitalized for heart failure in Japan: A report from the Japanese cardiac registry of heart failure in cardiology (JCARECARD). Circ J 2009; 73: 2084-2090.

10. Stevenson WG, Stevenson LW, Middlekauff HR, Fonarow GC, Hamilton MA, Woo MA, et al. Improving survival for patients with atrial fibrillation and advanced heart failure. J Am Coll Cardiol 1996; 28: $1458-1463$.

11. The CONSENSUS trial study group. Effects of enalapril on mortality in severe congestive heart failure: Results of the COoperative North Scandinavian ENalapril SUrvival Study (CONSENSUS). $N$ Engl J Med 1987; 316: 1429-1435.

12. Morris JJ, Entman M, North WC, Kong Y, McIntosh H. The changes in cardiac output with reversion of atrial fibrillation to sinus rhythm. Circulation 1965; 31: 670-678.

13. Pozzoli M, Cioffi G, Traversi E, Pinna GD, Cobelli F, Tavazzi L. Predictors of primary atrial fibrillation and concomitant clinical and hemodynamic changes in patients with chronic heart failure: A prospective study in 344 patients with baseline sinus rhythm. J Am Coll Cardiol 1998; 32: 197-204.

14. Kotecha D, Holmes J, Krum H, Altman DG, Manzano L, Creland JGF, et al. Efficacy of $\beta$ blockers in patients with heart failure plus atrial fibrillation: An individual-patient data meta-analysis. Lancet 2014; 384: 2235-2243.

15. Kannel WB, Abbott RD, Savage DD, McNamara PM. Coronary heart disease and atrial fibrillation: The Framingham study. Am Heart J 1983; 106: 389-396.

16. JCS Joint Working Group. Guidelines for pharmacotherapy of atrial fibrillation (JCS 2013): Digest version. Circ J 2014; 78: 1997-2021.

17. Colilla S, Crow A, Petkun W, Singer DE, Simon T, Liu X. Estimates of current and future incidence and prevalence of atrial fibrillation in the U.S. adult population. Am J Cardiol 2013; 112: 1142-1147.

18. Ho KKL, Pinsky JL, Kannel WB, Levy D. The epidemiology of heart failure: The Framingham study. J Am Coll Cardiol 1993; 22(Suppl A): 6A-13A.

19. Ambrosy AP, Fonarow GC, Butler J, Chioncel O, Greene SJ, Vaduganathan $\mathrm{M}$, et al. The global health and economic burden of hospitalizations for heart failure. J Am Coll Cardiol 2014; 63: 1123 1133.

20. Sakata Y, Shimokawa H. Epidemiology of heart failure in Asia. Circ J 2013; 77: 2209-2217.

21. Shiba N, Nochioka K, Miura M, Kohno H, Shimokawa H; on behalf of the CHART-2 Investigators. Trend of westernization of etiology and clinical characteristics of heart failure patients in Japan: First 
report from the CHART-2 Study. Circ J 2011; 75: 823-833.

22. Miura M, Sakata Y, Miyata S, Nochioka K, Takada T, Tadaki S, et al. Usefulness of combined risk stratification with heart rate and systolic blood pressure in the management of chronic heart failure: A report from the CHART-2 Study. Circ J 2013; 77: 2954-2962.

23. Miura M, Shiba N, Nochioka K, Takada T, Takahashi J, Kohno H, et al. Urinary albumin excretion in heart failure with preserved ejection fraction: An interim analysis of the CHART 2 study. Eur J Heart Fail 2012; 14: 367-376.

24. Nochioka K, Sakata Y, Takahashi J, Miyata S, Miura M, Takada T, et al. Prognostic impact of nutritional status in asymptomatic patients with cardiac diseases: A report from the CHART-2 study. Circ $J$ 2013; 77: 2318-2326.

25. Sakata Y, Miyata S, Nochioka K, Miura M, Takada T, Tadaki S, et al. Gender differences in clinical characteristics, treatment and longterm outcome in patients with stage $\mathrm{C} / \mathrm{D}$ heart failure in Japan. Circ $J$ 2014; 78: 428-435.

26. Yancy CW, Jessup M, Bozkurt B, Butler J, Casey DE Jr, Drazner MH, et al. 2013 ACCF/AHA Guideline for the Management of Heart Failure: A Report of the American College of Cardiology Foundation/American Heart Association Task Force on Practice Guidelines. $J$ Am Coll Cardiol 2013; 62: e147-e239, doi:10.1016/j.jacc. 2013.05.019.

27. Lee DS, Gona P, Vasan RS, Larson MG, Benjamin EJ, Wang TJ, et al. Relation of disease pathogenesis and risk factors to heart failure with preserved or reduced ejection fraction: Insights from the Framingham heart study of the National Heart, Lung, And Blood Institute. Circulation 2009; 119: 3070-3077.

28. Austin PC. The performance of different propensity-score methods for estimating differences in proportions (risk differences or absolute risk reductions) in observational studies. Stat Med 2010; 29: 2137 2148.

29. R Core Team. R: A language and environment for statistical computing. Vienna: R Foundation for Statistical Computing, 2014. http:// www.R-project.org (accessed July 11, 2015).

30. Wang TJ, Larson MG, Levy D, Vasan RS, Leip EP, Wolf PA, et al. Temporal relation of atrial fibrillation and congestive heart failure and their joint influence on mortality: The Framingham heart study. Circulation 2003; 107: 2920-2925.

31. Jones DG, Haldar SK, Hussain W, Sharma R, Francis DP, RahmanHaley SL, et al. A randomized trial to assess catheter ablation versus rate control in the management of persistent atrial fibrillation in heart failure. J Am Coll Cardiol 2013; 61: 1894-1903.

32. Braunwald E. Shattuck lecture: Cardiovascular medicine at the turn of the millennium: Triumphs, concerns, and opportunities. $N$ Engl $J$ Med 1997; 337: 1360-1369.

33. Kannel WB, Belanger AJ. Epidemiology of heart failure. Am Heart $J$ 1991; 121: 951-957.

34. Rivero-Ayerza M, Scholte Op Reimer W, Lenzen M, Theuns DA, Jordaens L, Komajda M, et al. New-onset atrial fibrillation is an independent predictor of in-hospital mortality in hospitalized heart failure patients: Results of the EuroHeart Failure Survey. Eur Heart
J 2008; 29: 1618-1624.

35. Crijns HJ, Tjeerdsma G, de Kam PJ, Boomsma F, Gelder IC, Berg MP, et al. Prognostic value of the presence and development of atrial fibrillation in patients with advanced chronic heart failure. Eur Heart $J$ 2000; 21: $1238-1245$.

36. Wachtell K, Lehto M, Gerdts E, Olsen MH, Hornestam B, Dahlof B, et al. Angiotensin II receptor blockade reduces new-onset atrial fibrillation and subsequent stroke compared to atenolol. J Am Coll Cardiol 2005; 45: 712-719.

37. Ducharme A, Swedberg K, Pfeffer MA, Cohen-Solal A, Granger $\mathrm{CB}$, Maggioni AP, et al. Prevention of atrial fibrillation in patients with symptomatic chronic heart failure by candesartan in the Candesartan in Heart failure: Assessment of Reduction in Mortality and morbidity (CHARM) program. Am Heart J 2006; 152: 86-92.

38. Sakata Y, Shiba N, Takahashi J, Miyata S, Nochioka K, Miura M, et $\mathrm{al}$; on Behalf of the SUPPORT Trial Investigators. Clinical impacts of additive use of olmesartan in hypertensive patients with chronic heart failure: The supplemental benefit of an angiotensin receptor blocker in hypertensive patients with stable heart failure using olmesartan (SUPPORT) trial. Eur Heart J 2015; 36: 915-923.

39. Pena JM, ManFadyen J, Glynn RJ, Ridker PM. High-sensitivity C-reactive protein, statin therapy, and risks of atrial fibrillation: An exploratory analysis of the JUPITER trial. Eur Heart J 2012; 33: $531-537$.

40. Maggioni AP, Fabbri G, Lucci D, Marchioli R, Franzosi MG, Latini $\mathrm{R}$, et al. Effects of rosuvastatin on atrial fibrillation occurrence: Ancillary results of the GISSI-HF trial. Eur Heart J 2009; 30: $2327-2336$.

41. Macfarlane PW, Murray H, Sattar N, Stott DJ, Ford I, Buckley B, et al. The incidence and risk factors for new onset atrial fibrillation in the PROSPER study. Europace 2011; 13: 634-639.

42. Haywood LJ, Ford CE, Crow RS, Davis BR, Massie BM, Einhorn PT, et al. Atrial fibrillation at baseline and during follow-up in ALLHAT (Antihypertensive and Lipid-Lowering Treatment to Prevent Heart Attack Trial). J Am Coll Cardiol 2009; 54: 2023-2031.

43. Adabag AS, Nelson DB, Bloomfield HE. Effects of statin therapy on preventing atrial fibrillation in coronary disease and heart failure. $\mathrm{Am}$ Heart J 2007; 154: 1140-1145.

44. Lang RM, Bierig M, Devereux RB, Flachskampf FA, Foster E, Pellikka PA, et al. Recommendations for Chamber Quantification: A Report from the American Society of Echocardiography's Guidelines and Standards Committee with the European Association of Echocardiography, a branch of the European Society of Cardiology. J Am Soc Echocardiogr 2005; 18: 1440-1463.

\section{Supplementary Files}

Supplementary File 1

CHART-2 Study Investigators

Please find supplementary file(s);

http://dx.doi.org/10.1253/circj.CJ-15-0783 